\title{
The primacy of cognition in the manifestations of substance use disorders
}

\author{
Jean Lud Cadet ${ }^{1 *}$ and Veronica Bisagno ${ }^{2}$ \\ ${ }^{1}$ NIDA Intramural Program, Molecular Neuropsychiatry Research Branch, Baltimore, MD, USA \\ 2 Instituto de Investigaciones Farmacológicas (ININFA-UBA-CONICET), Buenos Aires, Argentina \\ *Correspondence: jcadet@intra.nida.nih.gov \\ Edited by: \\ Yun Chen, US Army Medical Research Institute of Chemical Defense, USA \\ Reviewed by: \\ Charles W. Wilkinson, University of Washington, USA
}

Keywords: substance abuse, cognition, impulsivity and self-control, pre-existing condition, frontal cortex

\section{INTRODUCTION}

Drug addiction is a serious public health problem that consists of a compulsive drive to take drugs despite repeated severe adverse consequences (1). Factors that influence the development and maintenance of addiction include access to drugs, social environment, genetic predisposition, and psychiatric comorbidities (2). Even in the absence of specific psychiatric diagnoses, certain psychological vulnerabilities may serve as substrates compounding the initiation of drug use and the development of substance use disorders. For example, individual who are sensationseekers, impulsive, or behavioral disinhibited appear more prone to develop addiction to both licit and illicit substances (36). In this context, it is to be noted that not all individuals who try these drugs become addicted as about only $20 \%$ of people who have tried drugs become addicts (7). It is also worth mentioning that repeated exposure to moderate to large doses of some of these illicit drugs may be associated with well-known neuropathological consequences $(8,9)$ that might not be either necessary or sufficient for the development and the maintenance of addicted states.

The accumulated evidence supports the view that a large number of substance users suffer from significant neuropsychological impairments (10). Neuroimaging studies in drug-dependent individuals have also documented significant functional and structural alterations in several brain regions (1). These regions include mesocortical, mesolimbic, and mesostriatal brain regions that are known to be impacted by administration of licit and illicit drugs in both clinical and preclinical studies (2). In what follows, we discuss the potential impact of illicit drugs on these brain regions and the associated cognitive consequences of these drugs. We then suggest that these cognitive consequences play primary roles in the maintenance of addiction across several classes of abused substances.

\section{PRE-EXISTING COGNITIVE DEFICITS IN SUBSTANCE USE DISORDERS}

Before elaborating the idea of druginduced cognitive changes in patients addicted to illicit drugs, it is important to briefly discuss the influence of potential premorbid deficits on the cognitive performance of some drugs abusers (11). For example, Ersche et al. (12) suggested that cognitive dysfunctions and impulsive personality traits are endophenotypes for drug dependence. Drug-dependent individuals were significantly impaired on all the tests used in their study and some of these cognitive deficits were also found to exist in first-degree relatives in the absence of drug abuse (12). Levels of impulsivity were also higher in drug-dependent individuals than in their siblings, indicating that chronic drug abuse further increases both anxiety and impulsive traits. Smith et al. (13) also reported that impairments in hemispheric lateralization during task performance were apparent in both drug-using subjects and their control siblings, with the siblings decreasing but the drug users increasing activity in relevant brain regions.

\section{ADDICTION AS A HYPERCONNECTION SYNDROME}

The prefrontal cortex (PFC) and the striatum participate in integrated functions that are modulated by glutamate (12) and dopamine (DA) (14). These functions include decision making (15), salience attribution and goal-directed behaviors (16), and inhibitory control of behaviors (17) that are subsumed by specific cortical subregions. Under normal circumstances, organisms consider many salient behaviors but must choose to perform one or the other by performing specific very fast calculations of cost/benefit ratios (18). These activities, including selection of actions based on their valuation, are thought to depend on the PFC (18). Nevertheless, successful completion of goaldirected behaviors such as searching for food or drugs must require more complex and extended sequences of actions that must be maintained despite obstacles and distractions. In people addicted to drugs, there seems to be a narrowing of goal selection, with substances of abuse becoming more salient than other choices (19). This narrowing might be dependent on abnormal dynamics of DA release in the PFC with subsequent effects on corticostriatal glutamate projections to the dorsal striatum that might be intimately involved in the compulsive manifestations of drug-taking behaviors (20, 21). In other words, although the initial effects of drugs might be to enhance DA release in various brain regions (22), repeated exposure to these drugs might lead to subsequent weaker DA release, tolerance to drug effects, followed by increased drug taking to recalibrate the functional interactions of the corticostriatal loops.

Pathological changes in the orbitofrontal cortex (OFC) might also 
be involved in the manifestation of addiction-related behaviors because it is relevant to outcomes related to primary reinforcers (23). OFC neurons encode details concerning the sensory properties of rewards, the size, and timing of past or future rewards (23). Impairments in the OFC result in compulsive behaviors and impulsivity (24). A potential role of the OFC in the maintenance of addiction is supported by the observation of loss of prefrontal gray matter in individuals with a long history of drug abuse (25). This discussion is also supported by the report of decreased striatal D2R availability, known to be located on the indirect striatal projecting neurons, in the striatum of cocaine and methamphetamine addicts $(26,27)$. It is thus not farfetched to suggest that unopposed actions of D1-like DA receptors through the direct basal ganglia pathway may promote states of hyperconnections within basal ganglionic/cortical functional and structural loops. These hypothesized hyperconnections might be responsible for several cognitive manifestations of addictive states.

\section{MANIFESTATIONS OF THE HYPERCONNECTION SYNDROME IMPULSIVITY}

Impaired self-control plays a fundamental role in drug-taking behaviors in addictive states (11). Impulsivity is often referred by the term "disinhibition," referring to the idea of top-down control mechanisms that suppress automatic or reward-driven responses (28). The early stages of recreational drug taking are thought to be due to personality characteristics that influence whether or not the individual will try a rewarding substance. As mentioned earlier, only a minority of these individuals become addicted (7). This fact implies that the rewarding effect of drugs is not the main factor in the development and maintenance of addiction (29). These data also suggest that other important factors might drive the impetus to continue to use or increase the quantity of drugs used by those who become addicted. These factors might include specific pre-existing subclinical or clinical cognitive dysfunctions that might have interfered with an individual's ability to resist drug-taking behaviors that are known to contribute to adverse life consequences.
The available evidence does support the thesis that impulsivity is a vulnerability marker for substance abuse (11, 12). Several studies have demonstrated that children of drug-using parents have elevated impulsivity before drug exposure and that impulsivity indices are strong and reliable predictors of drug initiation and drug-associated problems (11). Importantly, during the interval of drug taking while the addiction threshold might be broached, taking of substantial amounts of drugs might have produced additional changes in the brains of susceptible individuals, with resulting further progression of cognitive impairments that are well documented in several reports $(11,30-33)$. Of importance to this thesis, cognitive impairments have been shown to be greater in drug-dependent individuals compared with their siblings (12). The proposed drug-induced pathological and/or functional damage might be responsible for the perseverative aspects of drug-taking behaviors that are somewhat akin to the perseveration observed in patients with severe head traumas (34) or in patients with some demented states (35). This similarity might explain, in part, the perseverative taking of drugs when they are no longer reinforcing and/or when drug-taking behaviors are accompanied by severe psychosocial and medical consequences (23).

Interestingly, abnormalities have been identified in frontal networks that subsume poor self-regulation and impulse control in cocaine dependency. Specifically, cocaine users were reported to show stronger connectivity within the perigenual anterior cingulate cortex (ACC) social processing/“mentalizing" network (36). This study is compatible with previous findings of abnormal inhibitory control in cocaine users $(37,38)$. Of etiological significance, Kelly et al. (39) found increased but lower resting connectivity between the ACC and dorsolateral prefrontal cortex (DLPFC) in children and adolescents, respectively. This relationship was almost non-existent in adults (39). These observations suggest that the connectivity within these regions might be "pruned" with brain maturation during the aging process and that cocaine users might suffer from a regression of these maturational processes because of plastic effects of the drug. This is important because an efficient interaction of ACC and
DLPFC is needed for appropriate behavioral control (40). Therefore, the cognitive impulse control disorder observed in addicted patients might be secondary to drug-induced activation of developmental genes that regulate connectivity between various brain regions (41).

\section{ATTENTION}

Attention represents a number of intimate mechanisms that facilitate the filtering, selection, and processing of information (42). In substance users, there is substantial attentional bias toward substance-related cues (43). Attentional bias exists to a greater extent in people with highly compulsive patterns of drug taking (43). Demonstrations of attentional bias for substancerelated stimuli among experienced substance users are consistent with the view that classical conditioning is involved in their development because substancerelated cues are, by nature, associated with the effects of substances (44). Other studies have also documented drug-related deficits in attentional tests in cocaine addicts (32, 45, 46). Methamphetamine addicts also showed deficits on measures of sustained (47) and spatial (48) attention, with these deficits having been linked to methamphetamine-associated damage to the ACC and insular cortices (47). Thus, damage to these brain regions might play an important role in causing dysfunctions in attentional circuits that are critical to learning and memory processes that are important to remember specific therapeutic interventions, thereby increasing the rate of recidivism in addicted patients.

\section{DECISION MAKING}

Poor cognitive performance in areas of risk-taking and decision making may influence the degree to which illicit drug users engage in risky behaviors with consequent negative health consequences. Deficits in tests of decision making have been found in patients who suffer from marijuana (49, 50), cocaine (51), MDMA (52), and methamphetamine $(53,54)$ addiction. These deficits might be related to altered connectivity of the right insula to the dorsomedial PFC, inferior frontal gyrus, and DLPFC in cocaine-dependent subjects (55). Methamphetamine-dependent individuals also showed disrupted riskrelated processing in the ACC and insula 
(54). Moreover, occasional stimulant users also showed reward dysfunction during reinforcement-based decision making and greater activation in the ACC, inferior frontal gyrus, and dorsal striatum compared with control subjects (56). Therefore, drug addiction might be associated with altered functional connectivity in largescale neural networks that might serve to distort awareness, salience detection, and other functions that regulate various cognitive processes including decision making, with subsequent severe negative impacts on activities of daily living (55).

\section{CONCLUSION}

In summary, drug addiction is marked by mild, yet pervasive, cognitive disruptions that may cause the negative progression of the clinical course, threaten sustained abstinence (57), or increase recidivism $(58,59)$ associated with addiction to licit and illicit substances. Importantly, the existence of cognitive deficits identified in drug-dependent individuals suggests that cognitive disturbances might be predisposing risk factors for the development of drug dependence (12). Repeated exposure to various drugs of abuse might exacerbate some of these subclinical abnormalities by producing pathological changes in various brain regions including the PFC (2). Interestingly, recent neuroimaging studies have also documented cortical abnormalities in patients addicted to various classes of illicit substances (60). These cortical abnormalities, by causing disinhibition of various cortico-cortical, subcorticomidbrain, or subcortico-cortical pathways, might engender the formation of hyperconnected subcortical loops that might serve as substrates for the varied clinical manifestations of addiction. Better understanding of these neural connectioninduced cognitive deficits should help to develop better pharmacological and behavioral approaches for the treatment of substance use disorders.

\section{ACKNOWLEDGMENTS}

This paper is supported by the Intramural Research Program of the National Institute on Drug Abuse (NIDA), NIH, and DHHS. Veronica Bisagno is supported by grants PIP11420100100072 and PICT 2012-0924, Argentina.

\section{REFERENCES}

1. Volkow N, Li T-K. The neuroscience of addiction. Nat Neurosci (2005) 11:1429-30. doi:10. 1038/nn1105-1429

2. Volkow ND, Wang G-J, Fowler JS, Tomasi D. Addiction circuitry in the human brain. Annu Rev Pharmacol Toxicol (2012) 52:321-36. doi:10.1146/ annurev-pharmtox-010611-134625

3. Sher KJ, Bartholow BD, Wood MD. Personality and substance use disorders: a prospective study. J Consult Clin Psychol (2000) 68(5):818-29. doi:10.1037/ 0022-006X.68.5.818

4. Perugi G, Toni C, Frare F, Travierso MC, Hantouche E, Akiskal HS. Obsessive-compulsivebipolar comorbidity: a systematic exploration of clinical features and treatment outcome. J Clin Psychiatry (2002) 12:1129-34. doi:10.4088/JCP. v63n 1207

5. de Wit H. Impulsivity as a determinant and consequence of drug use: a review of underlying processes. Addict Biol (2009) 1:22-31. doi:10.1111/ j.1369-1600.2008.00129.x

6. Ersche KD, Turton AJ, Pradhan S, Bullmore ET, Robbins TW. Drug addiction endophenotypes: impulsive versus sensation-seeking personality traits. Biol Psychiatry (2010) 8:770-3. doi:10. 1016/j.biopsych.2010.06.015

7. Anthony JC, Warner LA, Kessler RC. Comparative epidemiology of dependence on tobacco, alcohol, controlled substances, and inhalants: basic findings from the National Comorbidity Survey. Exp Clin Psychopharmacol (1994) 2(3):244-68. doi:10. 1037/1064-1297.2.3.244

8. Krasnova IN, Cadet JL. Methamphetamine toxicity and messengers of death. Brain Res Rev (2009) 2:379-407. doi:10.1016/j.brainresrev.2009.03.002

9. Wilson JM, Kalasinsky KS, Levey AI, Bergeron C, Reiber G, Anthony RM, et al. Striatal dopamine nerve terminal markers in human, chronic methamphetamine users. Nat Med (1996) 6:699-703. doi:10.1038/nm0696-699

10. Yücel M, Lubman DI, Solowij N, Brewer WJ. Understanding drug addiction: a neuropsychological perspective. Aust N Z J Psychiatry (2007) 12:957-68. doi:10.1080/00048670701689444

11. Verdejo-García A, Lawrence AJ, Clark L. Impulsivity as a vulnerability marker for substance-use disorders: review of findings from high-risk research, problem gamblers and genetic association studies. Neurosci Biobehav Rev (2008) 4:777-810. doi:10. 1016/j.neubiorev.2007.11.003

12. Ersche KD, Turton AJ, Chamberlain SR, Müller U, Bullmore ET, Robbins TW. Cognitive dysfunction and anxious-impulsive personality traits are endophenotypes for drug dependence. Am J Psychiatry (2012) 9:926-36. doi:10.1176/appi.ajp. 2012

13. Smith DG, Jones PS, Bullmore ET, Robbins TW, Ersche KD. Cognitive control dysfunction and abnormal frontal cortex activation in stimulant drug users and their biological siblings. Transl Psychiatry (2013) 3:e257. doi:10.1038/tp.2013.32

14. Jocham G, Klein TA, Ullsperger M. Dopamine-mediated reinforcement learning signals in the striatum and ventromedial prefrontal cortex underlie valuebased choices. J Neurosci (2011) 5:1606-13. doi:10.1523/JNEUROSCI.3904-10.2011
15. Brass M, Ullsperger M, Knoesche TR, von Cramon DY, Phillips NA. Who comes first? The role of the prefrontal and parietal cortex in cognitive control. J Cogn Neurosci (2005) 9:1367-75. doi:10.1162/0898929054985400

16. Cardinal RN, Parkinson JA, Hall J, Everitt BJ. Emotion and motivation: the role of the amygdala, ventral striatum, and prefrontal cortex. $\mathrm{Neu}$ rosci Biobehav Rev (2002) 3:321-52. doi:10.1016/ S0149-7634(02)00007-6

17. Shimamura AP. Toward a cognitive neuroscience of metacognition. Conscious Cogn (2000) 9(2 Pt 1):313-23. doi:10.1006/ccog.2000.0450 discussion 324-6,

18. Matsumoto K, Suzuki W, Tanaka K. Neuronal correlates of goal-based motor selection in the prefrontal cortex. Science (2003) 5630:229-32. doi:10. 1126/science. 1084204

19. Berke JD, Hyman SE. Addiction, dopamine, and the molecular mechanisms of memory. Neuron (2000) 3:515-32. doi:10.1016/S0896-6273(00) 81056-9

20. Belin D, Everitt BJ. Cocaine seeking habits depend upon dopamine-dependent serial connectivity linking the ventral with the dorsal striatum. Neuron (2008) 3:432-41. doi:10.1016/j.neuron.2007. 12.019

21. Krasnova IN, Chiflikyan M, Justinova Z, McCoy MT, Ladenheim B, Jayanthi S, et al. CREB phosphorylation regulates striatal transcriptional responses in the self-administration model of methamphetamine addiction in the rat. Neurobiol Dis (2013) 58:132-43. doi:10.1016/j.nbd.2013.05. 009

22. Volkow ND, Tomasi D, Wang G-J, Fowler JS, Telang F, Goldstein RZ, et al. Reduced metabolism in brain "control networks" following cocaine-cues exposure in female cocaine abusers. PLoS One (2011) 2:e16573. doi:10.1371/journal.pone.0016573

23. Lucantonio F, Stalnaker TA, Shaham Y, Niv Y, Schoenbaum G. The impact of orbitofrontal dysfunction on cocaine addiction. Nat Neurosci (2012) 3:358-66. doi:10.1038/nn.3014

24. Volkow ND, Fowler JS. Addiction, a disease of compulsion and drive: involvement of the orbitofrontal cortex. Cereb Cortex (2000) 3:318-25. doi:10.1093/ cercor/10.3.318

25. Matochik JA, London ED, Eldreth DA, Cadet JL, Bolla KI. Frontal cortical tissue composition in abstinent cocaine abusers: a magnetic resonance imaging study. Neuroimage (2003) 3:1095-102. doi:10.1016/S1053-8119(03)00244- 1

26. Volkow ND, Wang G-J, Fowler JS, Tomasi D, Telang F. Addiction: beyond dopamine reward circuitry. Proc Natl Acad Sci U S A (2011) 37:15037-42. doi:10.1073/pnas.1010654108

27. Martinez D, Slifstein M, Narendran R, Foltin RW, Broft A, Hwang D-R, et al. Dopamine D1 receptors in cocaine dependence measured with PET and the choice to self-administer cocaine. Neuropsychopharmacology (2009) 7:1774-82. doi:10.1038/ npp.2008.235

28. Aron AR, Durston S, Eagle DM, Logan GD, Stinear CM, Stuphorn V. Converging evidence for a fronto-basal-ganglia network for inhibitory control of action and cognition. J Neurosci (2007) 44:11860-4. doi:10.1523/ JNEUROSCI.3644-07.2007 
29. Piazza PV, Deroche-Gamonet V. A multistep general theory of transition to addiction. Psychopharmacology (2013) 3:387-413. doi:10.1007/s00213013-3224-4

30. Bolla KI, Cadet JL, London ED. The neuropsychiatry of chronic cocaine abuse. J Neuropsychiatry Clin Neurosci (1998) 3:280-9.

31. Bolla KI, Brown K, Eldreth D, Tate K, Cadet JL. Dose-related neurocognitive effects of marijuana use. Neurology (2002) 9:1337-43. doi:10.1212/01. WNL.0000031422.66442.49

32. Bolla K, Ernst M, Kiehl K, Mouratidis M, Eldreth D, Contoreggi C, et al. Prefrontal cortical dysfunction in abstinent cocaine abusers. J Neuropsychiatry Clin Neurosci (2004) 4:456-64. doi:10.1176/ appi.neuropsych.16.4.456

33. Cadet JL, Bolla KI. Chronic cocaine use as a neuropsychiatric syndrome: a model for debate. Synapse (1996) 1:28-34. doi:10.1002/(SICI)10982396(199601)22:1<28::AID-SYN3>3.0.CO;2-K

34. Coetzer R, Stein DJ, Toit PL. Executive function in traumatic brain injury and obsessivecompulsive disorder: an overlap? Psychiatry Clin Neurosci (2001) 2:83-7. doi:10.1046/j.1440-1819. 2001.00792.x

35. Thompson JC, Stopford CL, Snowden JS, Neary D. Qualitative neuropsychological performance characteristics in frontotemporal dementia and Alzheimer's disease. J Neurol Neurosurg Psychiatry (2005) 7:920-7. doi:10.1136/jnnp.2003.033779

36. Camchong J, MacDonald AW, Nelson B, Bell C, Mueller BA, Specker S, et al. Frontal hyperconnectivity related to discounting and reversal learning in cocaine subjects. Biol Psychiatry (2011) 11:1117-23. doi:10.1016/j.biopsych.2011.01.008

37. Kirby KN, Petry NM. Heroin and cocaine abusers have higher discount rates for delayed rewards than alcoholics or non-drug-using controls. Addiction (2004) 4:461-71. doi:10.1111/j.1360-0443. 2003.00669.x

38. Heil SH, Johnson MW, Higgins ST, Bickel WK. Delay discounting in currently using and currently abstinent cocaine-dependent outpatients and non-drug-using matched controls. Addict Behav (2006) 7:1290-4. doi:10.1016/j.addbeh. 2005.09.005

39. Kelly AMC, Di Martino A, Uddin LQ, Shehzad Z, Gee DG, Reiss PT, et al. Development of anterior cingulate functional connectivity from late childhood to early adulthood. Cereb Cortex (2009) 3:640-57. doi:10.1093/cercor/bhn117

40. Morishima Y, Okuda J, Sakai K. Reactive mechanism of cognitive control system. Cereb Cortex (2010) 11:2675-83. doi:10.1093/cercor/ bhq013

41. Cadet JL. Amphetamine recapitulates developmental programs in the zebrafish. Genome Biol (2009) 7:231. doi:10.1186/gb-2009-10-7-231
42. Adler CM, Sax KW, Holland SK, Schmithorst V, Rosenberg L, Strakowski SM. Changes in neuronal activation with increasing attention demand in healthy volunteers: an fMRI study. Synapse (2001) 4:266-72. doi:10.1002/syn.1112

43. Ersche KD, Bullmore ET, Craig KJ, Shabbir SS, Abbott S, Müller U, et al. Influence of compulsivity of drug abuse on dopaminergic modulation of attentional bias in stimulant dependence. Arch Gen Psychiatry (2010) 6:632-44. doi:10.1001/ archgenpsychiatry.2010.60

44. Field M, Cox WM. Attentional bias in addictive behaviors: a review of its development, causes, and consequences. Drug Alcohol Depend (2008) 97(12):1-20. doi:10.1016/j.drugalcdep.2008.03.030

45. Albein-Urios N, Martinez-González JM, Lozano O, Clark L, Verdejo-García A. Comparison of impulsivity and working memory in cocaine addiction and pathological gambling: implications for cocaine-induced neurotoxicity. Drug Alcohol Depend (2012) 126(1-2):1-6. doi:10.1016/j. drugalcdep.2012.03.008

46. Bolla KI, Rothman R, Cadet JL. Dose-related neurobehavioral effects of chronic cocaine use. J Neuropsychiatry Clin Neurosci (1999) 3:361-9.

47. London ED, Berman SM, Voytek B, Simon SL, Mandelkern MA, Monterosso J, et al. Cerebral metabolic dysfunction and impaired vigilance in recently abstinent methamphetamine abusers. Biol Psychiatry (2005) 10:770-8. doi:10.1016/j. biopsych.2005.04.039

48. Salo R, Gabay S, Fassbender C, Henik A. Distributed attentional deficits in chronic methamphetamine abusers: evidence from the attentional network task (ANT). Brain Cogn (2011) 3:446-52. doi:10.1016/j.bandc.2011.08.012

49. Bolla KI, Eldreth DA, Matochik JA, Cadet JL. Neural substrates of faulty decision-making in abstinent marijuana users. Neuroimage (2005) 2:480-92. doi:10.1016/j.neuroimage.2005.02.012

50. Verdejo-Garcia A, Benbrook A, Funderburk F, David P, Cadet JL, Bolla KI. The differential relationship between cocaine use and marijuana use on decision-making performance over repeat testing with the Iowa gambling task. Drug Alcohol Depend (2007) 1:2-11. doi:10.1016/j.drugalcdep.2007.02. 004

51. Bolla KI, Eldreth DA, London ED, Kiehl KA, Mouratidis M, Contoreggi C, et al. Orbitofrontal cortex dysfunction in abstinent cocaine abusers performing a decision-making task. Neuroimage (2003) 3:1085-94. doi:10.1016/S1053-8119(03) 00113-7

52. Hanson KL, Luciana M, Sullwold K. Rewardrelated decision-making deficits and elevated impulsivity among MDMA and other drug users. Drug Alcohol Depend (2008) 96(1-2):99-110. doi: 10.1016/j.drugalcdep.2008.02.003
53. Monterosso JR, Aron AR, Cordova X, Xu J, London ED. Deficits in response inhibition associated with chronic methamphetamine abuse. Drug Alcohol Depend (2005) 2:273-7. doi:10.1016/j.drugalcdep. 2005.02.002

54. Gowin JL, Stewart JL, May AC, Ball TM, Wittmann M, Tapert SF, et al. Altered cingulate and insular cortex activation during risk-taking in methamphetamine dependence: losses lose impact. Addiction (2013). doi:10.1111/add.12354

55. Cisler JM, Elton A, Kennedy AP, Young J, Smitherman S, Andrew James G, et al. Altered functional connectivity of the insular cortex across prefrontal networks in cocaine addiction. Psychiatry Res (2013) 1:39-46. doi:10.1016/j.pscychresns. 2013.02.007

56. Stewart JL, Flagan TM, May AC, Reske M, Simmons AN, Paulus MP. Young adults at risk for stimulant dependence show reward dysfunction during reinforcement-based decision making. Biol Psychiatry (2013) 3:235-41. doi:10.1016/j.biopsych. 2012.08.018

57. Garavan H, Hester R. The role of cognitive control in cocaine dependence. Neuropsychol Rev (2007) 3:337-45. doi:10.1007/s11065-007-9034-x

58. Aharonovich E, Nunes E, Hasin D. Cognitive impairment, retention and abstinence among cocaine abusers in cognitive-behavioral treatment. Drug Alcohol Depend (2003) 2:207-11. doi:10. 1016/S0376-8716(03)00092-9

59. Aharonovich E, Hasin DS, Brooks AC, Liu X, Bisaga A, Nunes EV. Cognitive deficits predict low treatment retention in cocaine dependent patients. Drug Alcohol Depend (2006) 3:313-22. doi:10. 1016/j.drugalcdep.2005.08.003

60. Goldstein RZ, Volkow ND. Dysfunction of the prefrontal cortex in addiction: neuroimaging findings and clinical implications. Nat Rev Neurosci (2011) 11:652-69. doi:10.1038/nrn3119

Received: 19 October 2013; accepted: 04 November 2013; published online: 18 November 2013.

Citation: Cadet JL and Bisagno V (2013) The primacy of cognition in the manifestations of substance use disorders. Front. Neurol. 4:189. doi: 10.3389/fneur.2013.00189

This article was submitted to Neurotrauma, a section of the journal Frontiers in Neurology.

Copyright (C) 2013 Cadet and Bisagno. This is an openaccess article distributed under the terms of the Creative Commons Attribution License (CC BY). The use, distribution or reproduction in other forums is permitted, provided the original author(s) or licensor are credited and that the original publication in this journal is cited, in accordance with accepted academic practice. No use, distribution or reproduction is permitted which does not comply with these terms. 